\title{
Effects of monensin level and roughage/concentrate ratio on ruminal fermentation in bovines*
}

\author{
P.H.M. Rodrigues ${ }^{1,4}$, W.R.S. Mattos ${ }^{2}$, P.M. Meyer ${ }^{3}$, \\ C.S. Lucci ${ }^{1}$ and L. Melotti ${ }^{1}$ \\ ${ }^{1}$ College of Veterinary Medicine and Animal Science, University of Sao Paulo-USP, Brazil \\ ${ }^{2}$ Agricultural College "Luiz de Queiroz", University of Sao Paulo-USP, Brazil \\ ${ }^{3}$ Brazilian Institute of Geography and Statistics-IBGE, Brazil
}

\begin{abstract}
Nine rumen-fistulated cows were used in a completely randomized design replicated three times to evaluate three monensin $(0,150$ and $300 \mathrm{mg} / \mathrm{animal} /$ day $)$ and three concentrate levels $(25,50$ and $75 \%)$ in a $3 \times 3$ factorial arrangement. Twenty-one day subperiods were used, the first sixteen for diet (Tifton hay+concentrate) adaptation. Monensin decreased DMI only in 50\%-concentrate diet $(\mathrm{P}<0.05)$ and did not influence total VFAs concentrations. For ruminal $\mathrm{pH}$, molar\% of VFAs, and $\mathrm{NH}_{3}-\mathrm{N}$ concentration collected 7 times/day, the responses to high level of monensin were higher in low-forage diets $(\mathrm{P}<0.05)$. Responses to low level of monensin were higher in high-forage diets $(\mathrm{P}<0.05)$.
\end{abstract}

KEY WORDS: cattle, fibre, ionophores, volatile fatty acids

\section{INTRODUCTION}

For a long time nutritionists have tried to manipulate rumen fermentation. This can be done by increasing propionic production, decreasing methanogenesis or proteolysis and deamination in the rumen. Initially, this objective was done through diet manipulation. However, the discovery of rumen active molecules has brought great perspectives on agricultural sciences (Bergen and Bates, 1984).

Ionophores are a class of compounds that have obtained considerable success as additives. However, responses reached with the use of ionophores are variable. This can be explained partially by different experimental conditions (Galloway et

\footnotetext{
${ }^{*}$ Supported by FAPESP and CNPq (Brazil)

${ }^{4}$ Corresponding author: e-mail: pmazza@usp.br
} 
al., 1993), as concentrate and ionophor level. This trial was carried out to study interaction between these two factors on monensin response.

\section{MATERIAL AND METHODS}

Nine dry Holstein cows (470 kg BW), fitted with ruminal cannulas, were used in a completely randomized design replicated three times to determine the effects of different doses of monensin on different forage to concentrate ratio diets. Treatments were constituted of three monensin (Elanco) levels (0,150 and 300 $\mathrm{mg} /$ animal/day) and three concentrate levels $(25,50$ and $75 \%)$ in a $3 \times 3$ factorial arrangement. Diet contained Tifton 85 hay, maize grain, soyabean meal and minerals.

Each subperiod lasted 21 days. Cows were fed twice daily at 07.00 and 16.00 h. Until d 16, cows were fed $115 \%$ of their daily intake of the previous day. From d 17 to 21 , cows were fed $100 \%$ of the mean daily intake obtained from d 12 to 16. Refusals and feed samples were collected every morning from d 17 until 21, pooled, and stored in sealed plastic bags at $-10^{\circ} \mathrm{C}$ for later analysis.

On $\mathrm{d} 21$, just prior to morning meal $(0 \mathrm{~h})$ and at 2, 4, 6, 8, 10, and $12 \mathrm{~h}$ postfeeding, samples containing $500 \mathrm{~mL}$ of ruminal fluid were taken. Ruminal $\mathrm{pH}$ was determined using a portable $\mathrm{pH}$ meter. Following this, $2 \mathrm{~mL}$ of fluid were added to $1 \mathrm{~mL}$ of sulphuric acid $1 \mathrm{~N}$ solution, and frozen at $-20^{\circ} \mathrm{C}$ for later determination of ammonia $\mathrm{N}$. After that, $50 \mathrm{~mL}$ of ruminal liquid were centrifugated at $2.000 \times \mathrm{g}$ for $15 \mathrm{~min}$, and $1 \mathrm{~mL}$ of the supernatant was added to $0.2 \mathrm{~mL}$ of formic acid and frozen for later determination of VFAs.

For intake data, variance analysis separated effects of concentrate level, monensin level, interaction and experimental subperiod. Effects of main factors were separated in linear and linearity deviation (quadratic) effects. Interaction was separated in linear effect for both factors $\left(\mathrm{Con}_{\mathrm{L}} \mathrm{Xmon}_{\mathrm{L}}\right)$, linear effect for concentrate level and deviation for monensin level $\left(\mathrm{Con}_{\mathrm{L}} \mathrm{Xmon}_{\mathrm{D}}\right)$, deviation for concentrate level and linear effect for monensin level $\left(\operatorname{Con}_{\mathrm{D}} \mathrm{Xmon}_{\mathrm{L}}\right)$, and deviation effect for both factors $\left(\mathrm{Con}_{\mathrm{D}} \mathrm{Xmon}_{\mathrm{D}}\right)$. Ruminal parameters were analysed as described, but added of split-plot factor. The surface equation was obtained by multiple regression procedure (Roush et al., 1979).

\section{RESULTS AND DISCUSSION}

Concentrate and monensin levels interacted for molar percentage of $\mathrm{C}_{2}, \mathrm{C}_{3}$, $\mathrm{C}_{4}$ and $\mathrm{C}_{2}: \mathrm{C}_{3}$ ratio, although monensin had no effect on total VFAs concentration (Table 1). Using low monensin levels (ex. $150 \mathrm{mg}$ ), as lower was the concentrate level of diet, the greater was the molar\% of $\mathrm{C}_{3}$ (increases of 2.85, 1.34 and 4.93 percentile units for 25,50 and $75 \%$-concentrate diets, respectively). However, 
Table 1. Dry matter intake and ruminal fermentation pattern obtained with treatments ${ }^{1}$

\begin{tabular}{|c|c|c|c|c|c|c|c|c|c|}
\hline \multicolumn{2}{|c|}{ Treatments } & \multicolumn{8}{|c|}{ Parameters } \\
\hline Con, $\%$ & Mon, mg & DMI & VFAs & $\mathrm{C}_{2}$ & $\mathrm{C}_{3}$ & $\mathrm{C}_{4}$ & $\mathrm{C}_{2} / \mathrm{C}_{3}$ & $\mathrm{pH}$ & $\mathrm{NH}_{3}-\mathrm{N}$ \\
\hline \multicolumn{10}{|c|}{ Interactions } \\
\hline \multirow{3}{*}{25} & 0 & 1.75 & 60.70 & 80.29 & 13.83 & 5.88 & 5.83 & 6.76 & 7.71 \\
\hline & 150 & 1.58 & 59.73 & 77.39 & 16.68 & 5.94 & 4.68 & 6.65 & 9.54 \\
\hline & 300 & 1.85 & 60.51 & 76.42 & 17.34 & 6.24 & 4.42 & 6.83 & 6.44 \\
\hline \multirow{3}{*}{50} & 0 & 2.52 & 73.45 & 73.23 & 16.62 & 10.15 & 4.43 & 6.44 & 10.35 \\
\hline & 150 & 2.18 & 62.94 & 73.52 & 17.96 & 8.53 & 4.11 & 6.62 & 9.20 \\
\hline & 300 & 1.67 & 64.88 & 71.38 & 21.01 & 7.61 & 3.42 & 6.57 & 7.87 \\
\hline \multirow{3}{*}{75} & 0 & 1.84 & 81.65 & 65.60 & 25.10 & 9.30 & 2.77 & 6.11 & 7.28 \\
\hline & 150 & 1.79 & 62.92 & 71.40 & 20.17 & 8.43 & 3.67 & 6.58 & 5.14 \\
\hline & 300 & 2.15 & 73.65 & 56.65 & 37.65 & 5.70 & 1.63 & 6.36 & 3.98 \\
\hline \multicolumn{10}{|c|}{ Main effects } \\
\hline 25 & & 1.73 & 60.31 & 78.03 & 15.95 & 6.02 & 4.98 & 6.75 & 7.89 \\
\hline 50 & & 2.12 & 67.09 & 72.71 & 18.53 & 8.76 & 3.99 & 6.54 & 9.14 \\
\hline \multirow[t]{4}{*}{75} & & 1.93 & 72.74 & 64.55 & 27.64 & 7.81 & 2.69 & 6.35 & 5.47 \\
\hline & 0 & 2.04 & 71.93 & 73.04 & 18.51 & 8.44 & 4.34 & 6.44 & 8.45 \\
\hline & 150 & 1.85 & 61.86 & 74.10 & 18.27 & 7.63 & 4.15 & 6.62 & 7.96 \\
\hline & 300 & 1.89 & 66.34 & 68.15 & 25.33 & 6.52 & 3.16 & 6.59 & 6.10 \\
\hline \multicolumn{10}{|l|}{ Mean } \\
\hline Mean & & 1.93 & 66.71 & 71.76 & 20.71 & 7.53 & 3.88 & 6.55 & 7.50 \\
\hline $\mathrm{CV}$ & & 21.15 & 21.20 & 10.41 & 37.08 & 26.58 & 32.10 & 4.56 & 55.25 \\
\hline \multicolumn{10}{|c|}{ Statistical probabilities } \\
\hline \multicolumn{10}{|c|}{ Concentrate } \\
\hline Linear & & NS & 0.0235 & 0.0001 & 0.0001 & 0.0118 & 0.0001 & 0.0002 & 0.0060 \\
\hline Deviat & n (D) & NS & NS & NS & NS & 0.0038 & NS & NS & 0.0019 \\
\hline \multicolumn{10}{|c|}{ Monensin } \\
\hline Linear & & NS & NS & 0.0148 & 0.0032 & 0.0075 & 0.0003 & NS & 0.0075 \\
\hline Deviat & $n(D)$ & NS & NS & 0.0383 & 0.0476 & NS & NS & NS & NS \\
\hline \multicolumn{10}{|c|}{ Interaction } \\
\hline \multirow{2}{*}{\multicolumn{2}{|c|}{$\begin{array}{l}\operatorname{Con}_{L} \mathrm{Xmon}_{\mathrm{L}} \\
\mathrm{Con}_{\mathrm{I}} \mathrm{Xmon}_{\mathrm{D}}\end{array}$}} & NS & NS & NS & NS & 0.0208 & NS & NS & NS \\
\hline & & NS & NS & 0.0092 & 0.0095 & NS & 0.0026 & 0.0115 & NS \\
\hline \multicolumn{2}{|c|}{$\operatorname{Con}_{D} \mathrm{Xmon}_{L}$} & 0.0126 & NS & NS & NS & NS & NS & NS & NS \\
\hline \multicolumn{2}{|c|}{$\operatorname{Con}_{n} \mathrm{Xmon}_{n}$} & NS & NS & NS & NS & NS & NS & NS & NS \\
\hline
\end{tabular}


using high doses of the product (ex. $300 \mathrm{mg}$ ), the highest response to monensin was obtained with larger proportion of concentrate in the diet (3.51, 4.39 and 12.55 percentile units for 25,50 and $75 \%$-concentrate diets, respectively). Effects of monensin were lower in high-roughage diets and low doses of product would be enough to produce maximum responses. In high-concentrate diets, responses were larger than in roughage diets, although it was necessary higher doses to produce good responses in those conditions.

Effects of monensin on ruminal $\mathrm{pH}$ were absent in high-roughage diets (-1.6 and $1.0 \%$ for 150 and $300 \mathrm{mg}$, respectively), lower in mixed diets (2.8 and $2.0 \%)$ and higher in high-concentrate diets $(7.8$ and $4.1 \%)$. For $\mathrm{NH}_{3}-\mathrm{N}$, monensin decreased its concentration independent on concentrate level of diet.

Fibre level or monensin dose interacted for DMI. Concentrate level caused a curvilinear response, with larger intake for mixed diets, and monensin caused a linear response, decreasing DMI. In mixed diet, there was a decrease of $33.0 \%$ in DMI caused by monensin, which is high when compared to a decrease of $6.4 \%$ observed by Goodrich et al. (1984).

\section{CONCLUSIONS}

Responses to monensin vary with fibre level and product dose. Response to monensin is lower in high-fibre diet and lower dose is enough to produce maximum response. On the other hand, response to monensin is higher in lowfibre diet and higher dose is necessary to produce maximum response.

\section{REFERENCES}

Bergen W.G., Bates D.B., 1984. Ionophores: Their effect on production efficiency and mode of action. J. Anim. Sci. 58, 1465-1483

Galloway D.L., Goetsch A.L., Patil A., Forster L.A. Jr., Johnson Z.B., 1993. Feed intake and digestion by Holstein steer calves consuming low-quality grass supplemented with lasalocid or monensin. Can. J. Anim. Sci. 73, 869-879

Goodrich R.D., Garret J.E., Gast D.R., Kirick M.A., Larson D.A., Meiske J.C., 1984. Influence of monensin on the performance of cattle. J. Anim. Sci. 58, 1484-1498

Roush W.B., Petersen R.G., Arscott G.H., 1979. An application of response surface methodology to research in poultry nutrition. Poultry Sci. 58, 1504-1513 